\title{
MÁATAN K’OL: LA FLEXIBILIDAD EN EL RITUAL
}

\author{
Patricia María Balam Gómez \\ Ileana Beatriz Ruiz Alonso \\ Iván DE Jesús Solís SosA
}

Resumen: En el presente trabajo se describe y analiza el máatan k'ol, un ritual agrícola y colectivo realizado en el municipio de Santa Elena, al sur de Yucatán. Se destacarán la presencia de una mujer como especialista ritual, los objetivos del mismo y la ofrenda como elementos clave para entender los cambios y transformaciones en este tipo de rituales; sin perder de vista que en la cosmovisión maya, el monte, la milpa y el rancho son espacios masculinos.

Palabras claves: Máatan k'ol, ritual agrícola y colectivo, Municipio de Santa Elena, Yucatán, cosmovisión maya, especialista ritual.

Abstract: In the present work is described and analyzed the máatan k'ol, an agricultural and collective ritual realized in the municipality of Santa Elena, in the south of Yucatán. The presence of a woman as the ritual specialist, the objectives of the ritual and the sacrifice are emphasized as key elements in order to understand the changes and transformations in this type of rituals; without loosing the idea that in the Maya cosmos view, the forest, the milpa and the ranch are masculine spaces.

Keywords: Máatan k'ol, agricultural and collective ritual, municipality of Santa Elena, Yucatán, Maya cosmos.

Recepción: 23 de enero de 2008.

Aceptación: 9 de mayo de 2008 



\title{
MÁATAN K'OL: \\ LA FLEXIBILIDAD EN EL RITUAL ${ }^{1}$
}

\author{
Patricia María Balam Gómez \\ IleAna Beatriz Ruiz Alonso \\ Iván DE JEsús Solís SosA \\ Centro InAH-Yucatán
}

\section{Introducción}

El objetivo de este trabajo es presentar una aproximación a la flexibilidad como cualidad presente en el ritual del Máatan k'ol, ritual agropecuario y colectivofamiliar observado en el rancho San Lorenzo, a $25 \mathrm{~km}$ del municipio de Muna, Yucatán, y cercano a la zona arqueológica de Uxmal. ${ }^{2}$

Muna cuenta con una población total de 11449 habitantes, de los cuales 50\% son mayahablantes. Económicamente hablando, la población se distribuye en diferentes actividades relacionadas con los sectores productivos de la siguiente manera: $15 \%$ corresponde al sector primario, $7.5 \%$ al sector secundario y $12 \%$ al sector terciario. ${ }^{3}$ Un porcentaje no estimado de la población migra cotidianamente a la ciudad de Mérida, se emplea en trabajos de construcción y venta de productos agrícolas; otra parte de la población migrante se dirige a la zona del Caribe y en mayor proporción hacia distintas ciudades de los Estados Unidos de Norteamérica.

El ritual que nos ocupa es conocido en Muna como Máatan ${ }^{4} \mathrm{~K}^{\prime} \mathrm{l}^{5}$, en español "regalar y recibir en regalo" K'ol (caldo espeso hecho de masa de maíz); ceremo-

\footnotetext{
${ }^{1}$ Esta investigación ha sido posible gracias al cúmulo de información etnográfica generada por el equipo de investigadores de la Sección de Antropología Social del Centro inAн-Yucatán en el marco del Proyecto Etnografía de las Regiones Indígenas de México en el Nuevo Milenio.

${ }^{2}$ La información que se presenta proviene de cuatro fuentes principales: a) de la observación directa del ritual realizada los días 13 de mayo del 2006 y 5 de mayo de 2007, b) de entrevistas hechas a los organizadores y participantes del ritual en abril de 2007, c) de informes de campo escritos por Lourdes Rejón, Jorge Guzmán y Ma. Jesús Cen, investigadores que también observaron el ritual, d) de fotografías y videograbaciones. Todos estos datos fueron enriquecidos con comentarios y aportaciones sugeridas por: Ella F. Quintal, Martha Medina y Fidencio Briceño.

${ }^{3}$ INEGI. Tabulados Básicos del XII Censo General de Población y Vivienda, 2001.

${ }^{4}$ Matan 1. "lo así recibido de gracia o de limosna o lo impetrado o alcanzado de gracia, privilegio; [... 5: limosna que se recibe 2; privilegio, don que se recibe 3: don y gracia y merced recibir; 7: limosna, regalo [...] 2. MAAT 9: préstamo, dádiva, regalo alcanzar, recibir de favor o limosna 10: limosna [...]" (Barrera et al.; 1980: 411 y 505-506).

K'ol 2,5: "(Tipo de guiso con caldo denso, que se hace con masa de maíz, de trigo o cualquier otro material) (...) 13 nem: amasijo espeso, hecho de masa de maíz y en algunos casos de harina de trigo, que se emplea cocido y condimentado como parte (o salsa) de ciertos platillos confeccionados con carne, principalmente de aves. (Barrera et al., 1980: 411 y 505-506).

${ }^{5}$ Las cosechas pueden ser de maíz, cítricos, miel y la producción de ganado.
} 
nia maya realizada para agradecer por las cosechas recibidas durante el año o porque los productos fueron vendidos satisfactoriamente, principalmente maíz, cítricos, miel, ganado y sandía; según la creencia, efectuar este ritual trae como consecuencia una mayor prosperidad a la familia que ofrece el Máatan k'ol. Esta ceremonia es conocida también como "primicia" porque los primeros frutos son ofrendados a las respectivas deidades.

Los encargados de "ofrecer" o "entregar" los productos generalmente son un J-meen (sacerdote maya) o alguna persona que conoce la naturaleza del "trabajo". Como ofrendas principales, éstos elaboran saka, ${ }^{6} \mathrm{k}^{\prime} \mathrm{ol}$ y yaach, ${ }^{7}$ e imploran los favores de los dioses mediante las plegarias y comportamientos de respeto. Por otra parte, la organización y el patrocinio del ritual recae en grupos familiares o en sociedades agrícolas; en el primer caso, el gasto proviene del jefe de familia; en el segundo, los organizadores acostumbran cooperar igualitariamente con la entrega de aves, manteca, maíz, dinero y otros insumos. Cualquiera que sea la situación, la norma común es dar algo, ya sea fuerza de trabajo o colaboración en especie; en este caso, se organizó por un grupo familiar y por regla general de intercambio, cuando se entrega un ave viva, la mitad es devuelta después de haber sido cocinada y ofrendada.

\section{La flexibilidad en el ritual}

En contraposición a la concepción que califica a los rituales como prácticas reiterativas, propias de "una conducta formal prescrita en ocasiones no dominadas por la rutina tecnológica, y relacionada con la creencia en seres o fuerzas místicas..." (Turner, 1999:21), en este primer acercamiento nos proponemos estudiar la flexibilidad como un aspecto siempre presente en el ritual, entendiendo como tal la "posibilidad de orientar las normas en función de las expectativas o demandas de los participantes" (Galinier, 2005).

En dicha concepción, priva la idea de que los rituales son la respuesta a las circunstancias que inciden en la vida cotidiana, enfermedades, pobreza, crisis individuales, la situación política, etcétera. En este sentido, el ritual se construye y reconstruye con base en dos tipos de normas: a) normas de organización, aquellas que identifican y dan forma a un ritual; y b) normas de orientación, aquellas que pueden ser modificadas para la consecución de un fin.

Dicho lo anterior, se anticipa que la flexibilidad se verá expresada con mayor proporción en los detalles y no en la estructura general del ritual. En lo que al Máatan K'ol respecta, la flexibilidad se observa en cuatro aspectos: a) en las

\footnotetext{
6 'Saka', sakah o sak-ha': bebida hecha con masa de maíz molido y agua únicamente. Bebida muy semejante al pozol con la diferencia de que el maíz se cocina sin llegar a suavizarse así, la bebida es arenosa y se conserva por más tiempo” (Barrera et al., 1980: 709).

${ }^{7}$ Fidencio Briceño. También puede entenderse como "Yach' wah: migas de pan cocido. Amasar con la mano, estrujar los dedos, mezclar, restregar, incorporar” (Barrera et al., 1980: 961).
} 
características de la especialista ritual, b) en el modo de hacer el sacrificio, c) bendición de la casa y d) en el patrocinio del ritual y en las normas que rigen el sistema de intercambio.

\section{El máatan k’ol}

Año con año, en mayo, cuando los campesinos están en la espera de la nueva siembra, don Gilberto $\mathrm{Nah}^{8}$ Paredes, su familia y algunos invitados residentes en Muna, se dan a la tarea de cumplir con el compromiso de llevar a cabo el máatan $k$ 'ol. Desde hace más de 25 años, la familia Nah acostumbra realizar la ceremonia en el rancho de su propiedad, ${ }^{9}$ llamado "Rancho San Lorenzo" éste abarca un total de 300 hectáreas que se destinan a la milpa, pastoreo y apicultura.

La familia Nah cuenta que todo empezó alrededor de 1980, un año favorable para el señor Lorenzo Nah (padre de don Gilberto), quien obtuvo buenas cosechas de miel y maíz, y logró incrementar el número de cabezas de ganado que poseía. Ante tal prosperidad, don Lorenzo decidió dar las gracias a Dios ofreciendo los productos obtenidos y para ello contrató a un j-meen de Muna al que llamaban "Don Lol j-meen".

Pero en una ocasión un desacuerdo familiar hizo que la familia Nah desistiera de organizar la ceremonia y fue entonces que "un remolino de viento o 'mozón'" (monzón) derrumbó la casa del rancho.

Para evitar experiencias como la anterior, don Gilberto se propuso retomar y cumplir el compromiso que su papá estableció, y año con año contrata a un especialista ritual con los conocimientos requeridos para este tipo de ceremonia.

\section{La ceremonia}

Los preparativos para la ceremonia dieron comienzo aproximadamente un mes antes; los dueños del rancho desgranaron las mazorcas de maíz para el k'ol, seleccionaron las gallinas, contrataron a la rezadora (shamana), invitaron a familiares, amigos y a las señoras que iban a fungir como cocineras.

Un día antes de la ceremonia se preparó el maíz que sirvió para el saká y el $k$ 'ol, —generalmente el maíz utilizado es producto de las cosechas de las milpas del rancho.

\footnotetext{
${ }^{8}$ Debido a que una de las dos hijas de don Gilberto reside en Cancún y sus dos hijos varones viven en Estados Unidos de Norteamérica, la responsabilidad de la organización del Máatan k'ol recae en él y en su esposa. No obstante, sus hijos colaboran en la realización del ritual, sobre todo su hija quien en esta ocasión viajó para estar presente en la ceremonia.

${ }^{9}$ Originalmente el rancho fue adquirido en 1973 por el señor Lorenzo Nah, padre de don Gilberto, como parte de un programa federal de fomento a la ganadería. Posteriormente don Gilberto amplió la extensión del rancho comprando las tierras aledañas (Solís, Reporte de campo, s/f).
} 
El día de la ceremonia, se reunieron los invitados y familiares en el domicilio del propietario, para trasladarse al rancho. Las personas empezaron a llegar desde temprano, algunos de ellos traían una o dos gallinas, otras una pava o pavo.

La hija del dueño elaboró minuciosamente una lista con los nombres de donadores y colaboradores para asegurarse que todos recibieran su porción de la ofrenda al final de la ceremonia. Se observó que la gran mayoría de los asistentes a la ceremonia eran parientes y amigos de la familia del propietario del rancho, en muy escaso número, vecinos.

\section{El espacio ritual}

El lugar escogido para llevar a cabo el ritual fue un espacio amplio (aprox. $50 \mathrm{x}$ $50 \mathrm{~m}$ ) donde confluyen el corral, parte del potrero y la casa principal del rancho. Del lado norte está el corral, al sur un monte perteneciente al mismo rancho, al oriente el potrero y al poniente la casa; este espacio se ubica en la "entrada" del rancho.

La mayor parte de los participantes se concentraron a un costado del corral y del potrero, viéndose claramente una división por grupos de trabajo: torteadoras, cocineras, encargadas del altar, cortadores de leña, señores disolviendo la masa para el $k$ 'ol, etcétera.

La mesa-altar donde se iban a pronunciar los rezos y oraciones se colocó al oriente; consistió en una mesa de madera con un mantel color anaranjado con motivos de frutas; sobre él, cuatro floreros de madera: dos de ellos con flores de plástico y otros dos con flores naturales, seis jícaras, dos veladoras, la imagen enmarcada de San Lorenzo y dos incensarios de barro. Debajo de la mesa-altar se encontraban unos bacales (huesos de la mazorca), resultado del desgrane de las mazorcas que sirvieron para la elaboración de la masa para el saká.

Al llegar al rancho, todos depositaron sus animales en la alambrada que delimita el potrero; la shamana, con ayuda de su esposo, se dio a la tarea de sacrificarlos, colgándolos de las patas y cortando con un cuchillo la garganta a las gallinas y a los pavos la lengua para su desangramiento. En esta actividad participaron la shamana, su esposo y dos o tres señoras más.

\section{Preparación de la comida}

Desde la llegada al rancho una de las prioridades fue la preparación de comidas. Para ello se distribuyeron cuatro espacios donde las actividades se dividieron por grupos pequeños:

1. Mesas para desplumar y cortar aves: las mujeres se dedicaron a desplumar y "beneficiar" a las aves; aunque no es común, los hombres adultos y ancianos también participaron con este grupo de trabajo. 
2. Dos mesas para tortear: las mujeres ancianas elaboraron pimes, tortillas gruesas hechas a mano especialmente para el yáach'. Se organizaron en grupos de tres o más para hacer, cocer y despedazar los pimes.

3. Mesas para preparar condimentos y verduras: espacio de hombres y mujeres, con participación de jóvenes; se turnaron para triturar en un molino de mano el achiote, la pimienta, el clavo y el chile.

4. Cuatro fogones: empleados para cocer gallinas, pavos y para elaboración de k'ol y yáach'. Conforme las gallinas y pavos se cocieron se sacaron de los calderos para colocarlos sobre mesas de plástico, cerca del altar. Las gallinas y pavos tomaron un tono rojizo debido a la pasta de achiote con que se cocieron. La rezadora extrajo los hígados, corazones y patas de las aves cocidas para cortarlos y ponerlos en una cubeta. Estas vísceras fueron agregadas al yáach. Para el k'ol los señores vertieron la masa diluida a los caldos hervidos; ellos se encargaron porque se necesita la fuerza para mover constantemente la mezcla con ayuda de unos palos.

\section{Ofrenda de Saká}

A media mañana, la rezadora agregó seis jícaras a la mesa-altar: dos al norte, dos al sur y dos al oriente; después encendió cuatro cigarros: dos colocados al poniente, uno al norte y otro al sur. Otros elementos para la ofrenda fueron dos veladoras, agua bendita, dos incensarios, ramas de sipché (Bunchosia swartziana Griseb), una botella de ron e incienso.

Debajo de la mesa colocó dos cubetas llenas con saká desleído y el agua sobrante de dicha elaboración. En el transcurso de la ofrenda de saká, se fueron agregando más elementos del ritual como saká en masa, hojas de epazote y un atado de bacales de donde se obtuvo maíz.

La rezadora tomó uno por uno los cuatro cigarros, los encendió directamente del brasero, aspiró un par de bocanadas y colocó sobre la superficie de la mesa dos cigarros formando ángulos al nororiente y suroriente. Los cigarros —además del saká y la comida - se pusieron como ofrenda a los aluxes, la rezadora explicó que "desde la antigüedad" se le ofrece a estos seres en rituales como el observado: "cigarros, porque dicen, que antiguamente a los duendes se les da su cigarro, que su licor, que su comida, su bebida —es eso el saka y el k'ol, que es así está dando su comida" (Marcelina Narváez, Muna, Yuc., 13 de mayo de 2006).

Luego puso pequeñas ramas de sipché en los cuatro pies de la mesa, separó un racimo para remojar en agua bendita y asperjar cada ofrenda.

Cuando todo estuvo dispuesto sobre la mesa, la rezadora pronunció las oraciones para la ofrenda de saka'. Después de las reverencias, sostuvo cuatro pequeñas jícaras vacías para luego levantarlas una por una; primero las dos del norte, luego la dos del sur; enseguida hizo la señal de la Cruz a cada jícara, después de asentarlas nuevamente a la mesa. Enunció algunas palabras en maya, 
una oración a San Martín Caballero y asperjó el altar con agua bendita y hojas de sipché. Acto seguido tomó la botella de ron y derramó cierta cantidad para combinar con el saká, lo mezcló y bebió una cantidad pequeña.

Después, llamó a don Gilberto quien se aproximó al altar, recibió la jícara de manos de la rezadora, bebió y convidó a su esposa. Don Gilberto a su vez también convidó a otros señores que se encontraban en el área de desplumado de aves. Después de beber éstos, comenzaron a beber las demás señoras trabajadoras.

En términos del nombre del ritual, observamos un primer episodio de máatan, pues si nos apegamos al término en maya, corresponde a "regalar". Mientras tanto, la comida continuó preparándose en los espacios asignados para eso.

\section{Oraciones al interior de la casa del rancho}

Después de compartir la ofrenda de saká, la rezadora y una de las hijas de don Gilberto se dirigieron a la casa (lado poniente del rancho). Estas oraciones se realizaron únicamente en mayo de 2006 y fue a petición de la hija de don Gilberto, porque ella sintió "mal viento" en la casa, por eso la rezadora intervino con sus oraciones para evitar enfermedades o miseria. Se inició el trabajo dentro de la casa, partiendo del sur, mientras la acompañante sahumó la pared, la especialista comenzó una oración a San Martín Caballero. Luego la rezadora pronunció el Credo, una Oración y al finalizarla, pidió a la acompañante la repitiera. La rezadora continuó con unas palabras en maya y se santiguó. Observamos nuevamente la petición del "favor" para alejar la miseria, la sal y atraer el trabajo, salud, felicidad y sustento.

\section{Ofrenda de comida}

Cocidos los alimentos, la rezadora anunció que en ese momento daría inicio la ofrenda de comida. Todos se acercaron al toldo que cubrió del sol al espacio donde se encontraba el altar. Algunas señoras colocaron sillas y las dispusieron de manera que quedaron frente a las mesas sobre las cuales yacían las 27 aves, los tres peroles con k'ol, uno de yáach y una olla con chile preparado. Al pie de la mesa-altar también colocaron los residuos de masa de k'ol. Nada de las sobras se tiró, todo forma parte de la presentación en la mesa-altar.

La rezadora quemó incienso e indicó que cada persona presente sostuviera una vela encendida; inició la "entrega" con un rezo en lengua maya que incluía palabras de agradecimiento "por compartir con la familia".

Prosiguió enunciando plegarias en español que incluyeron oraciones comúnmente empleadas en los rosarios y novenas que los católicos acostumbran. La primera plegaria fue dirigida a Dios y a la virgen María y a la Virgen de Fátima. 
Luego pronunció la segunda plegaria dirigida a san Martín Caballero, la tercera plegaria dirigida a santa Margarita y la Virgen María.

Durante la pronunciación de las plegarias, había momentos en los que la rezadora permaneció de pie con la cabeza inclinada, en una actitud reverencial. En esta posición pronunciaba las oraciones y cánticos en las que era necesaria la partición de los presentes. La rezadora culminó dando las gracias a los presentes. Para recibir sus respectivas raciones, la gente hizo una fila donde se les entregó su comida. A cada persona se le dio una porción de carne, k'ol y yáach'.

En el extremo opuesto de la rezadora, se encontraban don Gilberto y su esposa, sosteniendo velas encendidas. Sobre la participación de los dueños del rancho, llama la atención la manera en la que los participantes interpretaron la forma tomada por la parafina derramada de las velas que sostenía la esposa de don Gilberto. Sobre la tierra se habían formado dos figuras que semejaban dos letras $C$ y $N$, ante el asombro de la concurrencia la rezadora intervino aclarando que podría significar "Cristo con nosotros" o "Cristo Nuestro" e interpretó este hecho como la manifestación de la presencia de Dios.

\section{Análisis del ritual}

\section{a) Las características de la especialista ritual}

Desde hace 20 años, aproximadamente, no existen J-meeno'ob en Muna, sino personas que saben hacer el trabajo de un J-meen. El último J-meen reconocido emigró a la ciudad de Mérida y las ceremonias realizadas después de este suceso fueron oficiadas por especialistas de poblaciones circunvecinas como Santa Elena, Ticul, Opichén, Pustunich y Bolonchén.

En Muna cada vez es más difícil encontrar especialistas o personas que oficien rituales. Las razones de esta escasez son diversas y pueden estar relacionadas con fallecimientos, enfermedades o desuso del oficio. La ausencia o carencia de J-meeno'ob se relaciona con otro fenómeno poco frecuente en Yucatán, la aparición de mujeres que se convierten en especialistas de rituales agrícolas. Este hecho es particularmente relevante, sobre todo cuando investigadores como Alfredo Barrera Vázquez (1973) Santiago Domínguez Aké (1996) e Hilaria Máas Collí (1991) y otros, interesados en cuestiones de rituales agrícolas, afirman que las ceremonias vinculadas con el monte y el trabajo agrícola son tareas del hombre, como consecuencia la participación de la mujer es limitada y en ocasiones considerada como contaminante de la acción ritual.

No obstante, los habitantes de Muna aprueban el conocimiento de personas como la rezadora, una mujer que se considera una especialista diferente a los J-meeno’ob, llamándose a sí misma "religiosa", "shamana” 10 o "rezadora”. Esta

${ }^{10}$ Sobre este punto, es preciso mencionar que la rezadora empezó a reconocerse "shamana" por recomendación de dos jóvenes estudiantes provenientes del centro de la República Mexicana. 
necesidad de identificarse como algo distinto a los J-meeno'ob es, en parte, resultado de los conflictos entre su práctica como "shamana" y la formación católica que por años ha recibido.

Tal conflicto se hace más evidente cuando la gente la señala como "bruja”, al grado que consideró necesario obtener el consejo y permiso del sacerdote de Muna para continuar entregando ofrendas a deidades o seres sobrenaturales no propios del catolicismo oficial.

Lo anterior marca la pauta en el desarrollo de los rituales oficiados por la rezadora, particularmente en las oraciones que emplea para ofrendar la comida y en su exégesis acerca del sacrificio por desangramiento.

Pese a la constante contradicción en la que se ve envuelta, la rezadora legitima su prestigio y práctica shamánica a través de ciertos acontecimientos que ella misma califica como inexplicables. Ejemplo de ello son las experiencias oníricas ${ }^{11}$ y premoniciones que se presentan días antes de que oficie una ceremonia: "Empecé a pensar, creo que de tanto pensar y pensar cómo lo voy a hacer, y si no está salado, y si me sale mal, y si esto y si lo otro. Y tuve un sueño, entonces soñé que estoy trabajando así como si yo fuera una experta, estoy haciendo ese trabajo [...] Y así cada noche soñaba, soñado lo hacía, soñaba cómo voy a hacer". (Marcelina Narváez; Muna, Yuc. 17 de abril 2007).

Mediante los sueños, la rezadora recibe de Dios las instrucciones necesarias para efectuar las ceremonias que oficia, por lo tanto se considera que los sueños son el canal que la divinidad emplea para transmitirle conocimientos útiles en la elaboración de la ofrenda. Ocasionalmente, la rezadora interpreta sus sueños como presagios que anuncian la proximidad de un "trabajo", es decir, la realización de una ceremonia.

Otra forma de legitimación empleada por la rezadora es la eficacia de sus ceremonias; sobre todo aquellas en las que "logra" pacificar a los "malos aires" que aquejan lugares como pozos y aguadas. Precisamente, después de la curación de un pozo con "mal viento" fue que obtuvo mayor prestigio.

La presencia del "viento" como agente agresor, tiene aquí una connotación específica, apunta a aquellos seres o espíritus que habitan y protegen espacios cargados de energía y fuerza (la milpa, el monte, las cuevas, los cenotes, etc.) Estos entes, que en ocasiones reciben el nombre de "dueños", fueron descritos como remolinos, aluxes o culebras ${ }^{12}$ y se les atribuye la capacidad de incidir positiva o negativamente en la vida del ser humano.

11 Los J-meenoób son "los guardianes del orden cósmico" y como tales oficiantes de distintas ceremonias propiciatorias y terapéuticas que involucran a deidades ancestrales. En las narraciones que dan cuenta de la manera en la que cada J-meen se inicia como sacerdote, es común escuchar que reciben su “don” y su "instrucción” a través de sueños (Quintal et al., 2003: 287-288).

12 Un ejemplo de la forma en la que los "dueños" ejercen su poder, nos lo proporciona Santiago Domínguez Aké: “Cuando el milpero entierra el saka' juntamente con nueve pedazos de x-táabka 'anil en las pocetas donde siembra la sandía, cualquier persona que entre a su milpa con la intención de robarla al acercarse al pachpak'al verá que se dirige hacia él una serpiente con la lengua en constante movimiento [...] Ninguna de las serpientes muerde al 'ladrón' cuando pasa corriendo junto a ellas, 
El carácter ambivalente de los vientos puede ser negociado a través de rituales que sirven como causes para el diálogo entre el hombre y los vientos (Barrera Vázquez, 1973). Es decir, mediante ceremonias como el máatan k'ol, en las que se ofrecen y agradecen los primeros frutos de la cosecha, los hombres pueden procurar la benevolencia de los vientos y de esta forma asegurar la cosecha del próximo año. En caso contrario, el "mal viento" castiga o causa enfermedades a quien irrumpe en el "monte" sin pedir permiso o, como en el caso que aquí se presenta, falte a su compromiso de entregar ofrenda: "Fue como un aviso porque ya habíamos pasado las fechas en que acostumbramos hacer, entonces pasó un remolino, un tornado, que arrancó las láminas, las torció y hay hasta que no busqué. Y entonces, yo y mi esposa decimos 'creo es que fallamos', debido a eso pasó". (Gilberto Nah Paredes; Muna, Yuc. 17 de abril de 2007).

Las experiencias oníricas y la capacidad de dialogar con los "vientos" o "dueños", son similitudes que la rezadora comparte con los jmeno'ob, "los guardianes del orden cósmico" y como tales oficiantes de distintas ceremonias propiciatorias y terapéuticas que involucran a deidades ancestrales (Quintal y otros, 2003: 285-287).

\section{b) Sacrificio y ofrendas}

Llevar gallinas a las ceremonias agrícolas es costumbre en la mayoría de las comunidades del sur de Yucatán; la gente que asiste al evento lo hace a manera de colaboración, cuyo trasfondo es el intercambio con las deidades; estas aves son sacrificadas y posteriormente ofrendadas. No es "obligación" de los asistentes e invitados llevar un ave, porque el dueño del rancho solventa todos los gastos que conlleva la ceremonia, así la repartición (máatan) de la comida está garantizada para todos.

En el caso que hemos documentado, los preparativos para la ceremonia iniciaron aproximadamente un mes antes, el propietario contrató a la rezadora (shamana), invitó a familiares, amigos y a las señoras que iban a fungir como cocineras. También el trabajo se ofrenda y es parte del intercambio: se da trabajo y se recibe comida y bendiciones.

Para el sacrificio, las aves fueron puestas bajo la alambrada que delimita el potrero, momentos después la "shamana" pidió que las colgaran de las patas; en esta posición, les cortó la garganta a las gallinas y a los pavos la lengua, provocando el desangramiento.

La rezadora conoce y en ocasiones practica el procedimiento de sacrificio que los J-meeno'ob emplean en sus ceremonias, poniendo a las aves licor en el pico, al mismo tiempo que las estrangulan con las manos. Sin embargo, su exégesis está más apegada a la tradición que sobre sacrificio tiene el cristianismo, es decir, desangra a las aves: "porque Jesucristo murió de la misma manera, dio su sangre

porque realmente no son serpientes, son los 'señores viento' que se transforman en serpientes [...]" (Domínguez, 1996: 194-195). 
por nosotros, por nuestra salvación". ${ }^{13}$ A través de esta técnica, ella se diferencia de los J-meeno'ob, quienes — según versiones de la gente- pueden pactarse con seres malignos y hacer daño a las personas, especialmente por encargo de otro individuo y, por consiguiente, son temidos por algunas personas. Sin embargo, los jmeno'ob, también tienen cierto prestigio, precisamente por esa capacidad de trabajar con seres del monte como los vientos y los guardianes. No está de más agregar la rivalidad entre los mismos jmeno'ob, cuyas pugnas pueden derivar en la muerte de algún jmeen por otro "más poderoso". Esta vertiente "peligrosa" de la práctica "shamánica”, es un valor implícito en muchos rituales territoriales mayas, por la intervención de los seres del monte antes mencionados. En otras culturas, por ejemplo entre los mazahuas, según palabras de Galinier, esto corresponde al “discurso 'nocturno' (...) los temas más profundamente reprimidos que hablan de la angustia, el deseo, la violencia y de la muerte, en pocas palabras, el 'discurso del diablo'” (Galinier, 1990:253). No obstante, la práctica ritual proporciona la opción de elegir tanto las plegarias, las ofrendas o el modo de sacrificio que cada oficiante prefiera y mientras el especialista mantenga las fases rituales en el orden acostumbrado, el resultado generalmente es el esperado.

La manera de sacrificar degollando a las aves según la propuesta de Galinier, tiene que ver con aquellos puntos del cuerpo donde la energía se concentra más que en otras partes del mismo, el sacrificio:

Se presenta como [...] una especie de consagración [...] el degollamiento de las aves tiene una lógica dentro de la cosmovisión indígena, si bien, el sacrificio traduce la naturaleza limitada de la energía, la fatalidad de su agotamiento revela el carácter discreto de la distribución de los centros de lo que es el sacrificio, pues la cabeza, los pies, el sexo son puntos donde la fuerza se concentra de manera privilegiada y son objeto de actos específicos de sacrificio (Galinier, 1990: 254-255).

Todo objeto de sacrificio sufre una metamorfosis: "si el sacrificio no significa verdaderamente la pérdida del objeto es porque sufre una metamorfosis que lo convierte en algo diferente de lo que era”. (Galinier, 1990: 254-255). En este sentido puede decirse que el propietario también forma parte del sacrificio para las deidades sobrenaturales; simbólicamente se "da" a Dios por medio del ritual y ante los demás aparece como persona generosa. Agradece y comparte lo que ha recibido (las cosechas, prosperidad económica) con los asistentes, familiares y amigos quienes también gozan de las bendiciones y beneficios de esos entes a quienes se ofrenda.

Las ofrendas fueron dirigidas a Dios, a los aluxo'ob ${ }^{14}$ y a los vientos, pues todos son seres sagrados y a cada uno se le "respeta", aunque de manera

\footnotetext{
13 Rezadora Marcelina Narváez, Muna, Yucatán, 13 de mayo de 2006.

${ }^{14}$ Alux o arux: enano legendario (mitológico) (Barrera Vázquez, Diccionario maya Cordemex, 1980 :
} $15)$. 
jerárquica primero se le ofrenda a Dios, pues él creó todo, incluyendo los vientos. ${ }^{15}$

Las ofrendas combinaron de diferentes maneras y momentos: alimentos, bebidas, oraciones, incienso. La disposición de ofrendas en el altar sugiere reglas flexibles en determinados aspectos:

a) Sobre el altar, la rezadora reservó los elementos "buenos" para Dios únicamente; sin embargo, la disposición de cigarros, licor e incienso fueron explícitamente para otros destinatarios: los aluxo'ob. Si atendemos al discurso de la oficiante, estos seres no deberían estar presentes entre los receptores de ofrendas.

b) $\mathrm{Al}$ poner los sobrantes de las ofrendas debajo de la mesa (como el agua de saka'), la rezadora consideró un uso posterior, de carácter terapéutico contra los "malos vientos" que aquejan a niños o "remolinos" que aparecen en algún espacio del rancho. Sin embargo, esta idea no predomina en la cosmovisión de los participantes del ritual; obtuvimos otras exégesis respecto a la disposición de elementos debajo de la mesa, es decir, se colocaron dichos residuos asociados a su procedencia: la tierra.

Quintal señala que "es también común que la ceremonia más sencilla de solicitud de licencia, o de petición de algún favor, o de agradecimiento, etcétera, implique el ofrecimiento de saká". De esta manera la "'prenda mínima' de intercambio entre la sociedad y la divinidad es el saká"." La misma autora señala a la ofrenda de saká como el primero de los movimientos básicos de los rituales (Quintal y otros, 2003: 301).

Dentro de los aspectos estructurales del ritual, destacan las ofrendas acompañadas de súplicas en lengua maya y en voz baja, dirigidas a los "vientos"; distintas a las oraciones de tipo católico, dichas en español y en voz alta. Además, en estas últimas, la especialista enfatizó el trabajo hecho por las personas para elaborar los dones, identificando a cada familia suplicante. Las variaciones en el volumen de las oraciones pueden interpretarse como una forma de jerarquización de las deidades que la especialista aplica según su formación católica. Al respecto, Alessandro Lupo (1995) señala entre los aspectos formales de las oraciones, la relación de respeto hacia los interlocutores extrahumanos traducida en el aumento o disminución de la voz al pronunciar las oraciones.

En este caso, el campo de aplicación de las peticiones fue el rancho, que también forma parte de "la esfera extradoméstica [...] que tienen por objeto los

\footnotetext{
15 'Yo cuando ofrezco el saka' invoco a los cuatro vientos para que, que Dios cómo te diré Dios creó todo [...] Dios los creó hay malos, hay buenos, porque también existe el mal y yo lo que hago entonces pedirle a Dios que aleje los malos vientos en ese lugar donde yo trabajo y que venga el bien, que Dios creó los vientos también, es lo que nos da vida también porque es lo bueno, pues si también existe el malo, que nos hace daño, que se aleje" (Marcelina Narváez, Muna, Yucatán, 13 de mayo de 2006).
} 
riesgos y las actividades que el hombre enfrenta fuera del espacio controlado y protector de la casa (y del pueblo), entre los cuales destacan por su importancia las ocupaciones de carácter agrícola" (Lupo, 1995: 91).

Al momento de pronunciar las oraciones, la rezadora se concretó a "llamar" a las entidades involucradas para su petición. Invocó a determinados Santos y Vírgenes, ${ }^{16}$ para "sacar las sales, las malas suertes" del rancho.

Los dioses tomaron "la gracia" de las ofrendas del k'ol y del saka'. En el ámbito de los humanos, sorbió primero la rezadora, porque la bebida pudo "cargar viento"17 y hacer daño a quien no esté preparado para ahuyentarlos. Al finalizar esta entrega, el propietario del rancho tomó el saka' y posteriormente repartió la bebida entre los asistentes. En términos del énfasis del ritual, observamos un primer episodio del máatan, pues si nos apegamos al término traducido al español, uno de sus significados corresponde a "regalar y recibir en regalo".

\section{c) Bendición de casa}

Una de las "reglas de orientación" con una particular flexibilidad en el ritual fue la bendición de la casa, pues no tiene un carácter periódico; se hizo en mayo de 2006 a partir del surgimiento de "malas vibras" (sic.), por eso la rezadora intervino con sus oraciones para alejar enfermedades o miseria, causadas por dichas "vibras". Según Galinier, estas situaciones críticas tienen como respuesta un ritual; en este caso la familia aprovechó el Máatan K'ol para marcar dos campos de aplicación de las peticiones: el rancho por un lado y la casa por otro.

Hemos considerado al rancho como un espacio extradoméstico; sin embargo, la casa representa un espacio doméstico "entendida en el sentido literal de la vivienda $[\ldots]$ y en el sentido metonímico del grupo residencial que la ocupa" (Lupo, 1995: 91). Reiteradamente el destinatario principal de las oraciones fue Dios, acompañado de las mencionadas vírgenes y los santos.

\section{d) Patrocinio y normas de intercambio}

La comida figura entre los aspectos más importantes en este tipo de rituales; su preparación estuvo regida por prevenciones y restricciones: la habilidad de la rezadora para calcular ingredientes y tiempos de cocción sin probar, subrayó el carácter de primicia para los seres sobrenaturales. Nada se prueba o desecha

\footnotetext{
${ }^{16}$ Hemos mencionado a San Lorenzo, San Martín Caballero, Virgen María, Virgen de Fátima y Santa Margarita.

17 “[...] tiene que ser, primero lo pruebo, porque tienen miedo probar porque si tiene mal viento yo primero; si al principio tenía yo que hacerme una limpia con esas yerbas sipché porque es para ahuyentar los malos vientos, de sipché, para que no me haga daño; porque les digo, que a mi me hizo daño el rezo y tengo miedo; pero ya ahora con más confianza, ya no [...] estén, no” (Marcelina Narváez, Muna, Yucatán, 17 de abril de 2007).
} 
hasta que los dioses hayan recibido la "gracia". La eficacia del ritual dependió de la coordinación del trabajo, pues si algo salía mal, podía arruinarse todo.

Respecto a la participación de hombres y mujeres en la elaboración de comidas, destacó otra norma de intercambio de trabajo: se configuraron espacios con inversiones de roles rituales que en la cotidianidad no se practican, tal es el caso de los hombres desplumando aves o haciendo k'ol.

Una vez cocidos los alimentos, la oficiante entregó todo en nombre de cada una de las familias participantes en el ritual. Enunció plegarias en español que manifestaron explícitamente el intercambio de dones por trabajo, dinero, salud y felicidad para los dueños del rancho y participantes. Estas oraciones destacaron el campo de aplicación de las bendiciones hacia los apiarios y animales del rancho. La rezadora culminó dando las gracias a los presentes.

Podría decirse que en el Máatan K’ol existen requerimientos que pueden ser interpretados como normas o reglas de intercambio y de ellas hablaremos en lo siguiente:

a) Normalmente, se espera que las personas que entregan un ave, reciban al final de la ceremonia, la mitad de ésta después de que haya sido sacrificada y ofrendada en el ritual. La primera mitad se reparte y consume en el Máatan; la otra mitad es devuelta a la persona para que ésta la comparta con sus familiares. Se observa flexibilidad en la norma, derivada del deseo de los invitados por compartir una porción de la ofrenda con aquellas personas que no asistieron el día del ritual, por encontrarse trabajando o en otro pueblo.

b) Esto no aplica a las personas que en lugar de un ave entregan maíz, manteca e incluso dinero; la diferencia radica en recibir únicamente porciones de k'ol y yaach.

c) En ocasiones las personas que aportaron su trabajo piden a los organizadores la mitad de un ave ofrendada y prometen devolver un ave entera (y viva) para que se ofrende el siguiente año: "Eso se le dice en maya 'kuch pol'. Kuch cargar, Pol, cabeza...Pero lo que ellos quieren, a veces una promesa que hacen así para acción de gracias: una pava, una gallina, dos gallinas [...]" (Graciela Martín, Muna, Yucatán, 17 de abril de 2007).

De esta forma el dueño y los invitados entran en un circuito de intercambio en el que los organizadores reciben la "ayuda" por medio de la colaboración de insumos y en respuesta los invitados reciben una porción de la ofrenda o quedan "debiendo" un ave entera para el siguiente año.

\section{Conclusiones}

Los dueños y vientos de los terrenos, ranchos, milpas y de los solares se "acostumbran" a las ofrendas, por mínima que ésta sea. Los espacios "domesticados" 
por el ser humano, como corrales, gallineros y casas, ubicados dentro de esos terrenos también reciben la "bendición", (como parte del terreno mayor habitado por el hombre). Por tal motivo, la presencia de hombres, mujeres y niños, quienes están permanentemente habitando esos espacios, requiere un cuidado estricto de los llamados dueños y vientos, presentes cuando se deja de cumplir con las ofrendas. A partir de ese momento se hace necesario algún ritual para serenar esas fuerzas.

En Muna el Máatan K'ol es el ritual agrícola por excelencia, el carácter flexible del mismo viene dado en sus detalles y no en su estructura general; en este sentido, las características de la especialista en términos de su adscripción católica y el desempeño de su trabajo le dan ese carácter.

Si bien no hay un "formato" uniforme, existen elementos estructurales como la presencia del especialista ritual, los oferentes, el intercambio entre humanos y seres naturales y especialmente el máat'an o repartición, sin los cuales el ritual no sería considerado como tal. La flexibilidad permite que las normas que rigen el ritual se adecuen a las características particulares del oferente y oficiante o especialista ritual.

Con o sin especialista ritual, el intercambio de plegarias, comida, reverencias y especialmente el cumplimiento del compromiso, es fundamental en este tipo de rituales, de lo contrario puede perderse mucho más de lo que se ofrece. Se reparte, precisamente porque hay productos para compartir, en consecuencia ese ciclo regresa nuevamente al dueño del rancho, con más abundancia. 


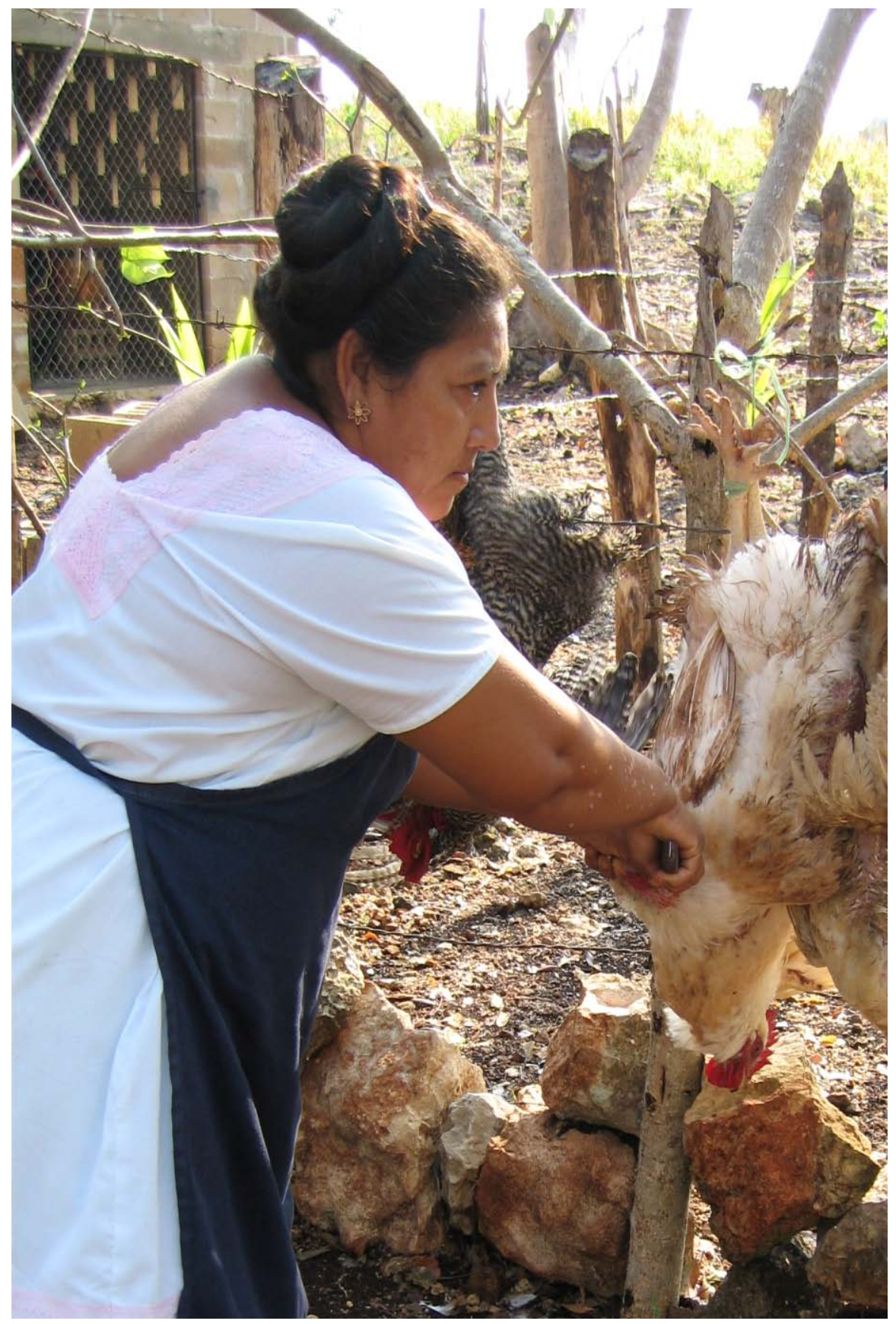

Fotografía 1. La reZadora durante el SACrificio de las aVes (Patricia María Balam Gómez, Muna, Yuc. 13 de mayo de 2006). 


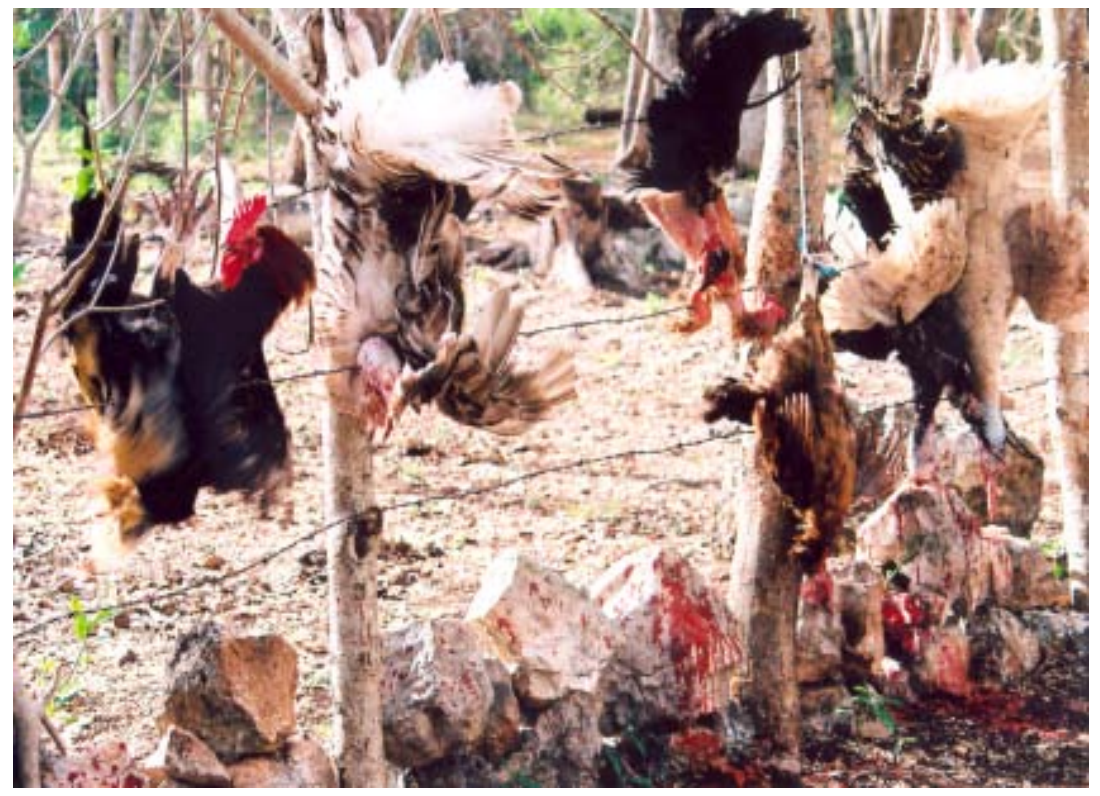

Fotografía 2. Sacrificio por desAngramiento (Ileana Beatriz Ruiz Alonso, Muna, Yuc. 5 de mayo de 2007).

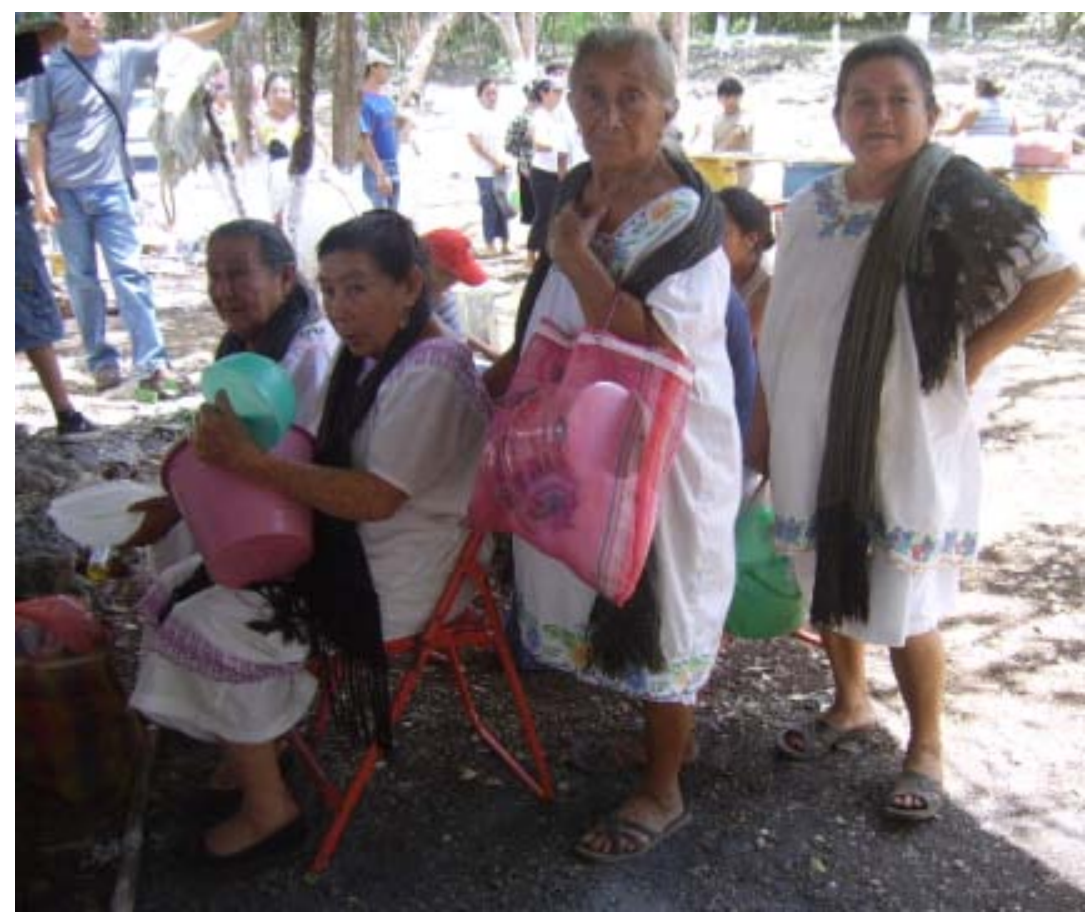

Fotografía 3. Mujeres haCIENDO FILA PARA RECIBIR LA PORCIÓN DE K'OL (Patricia María Balam Gómez, Muuna, Yuc. 5 de mayo de 2007). 


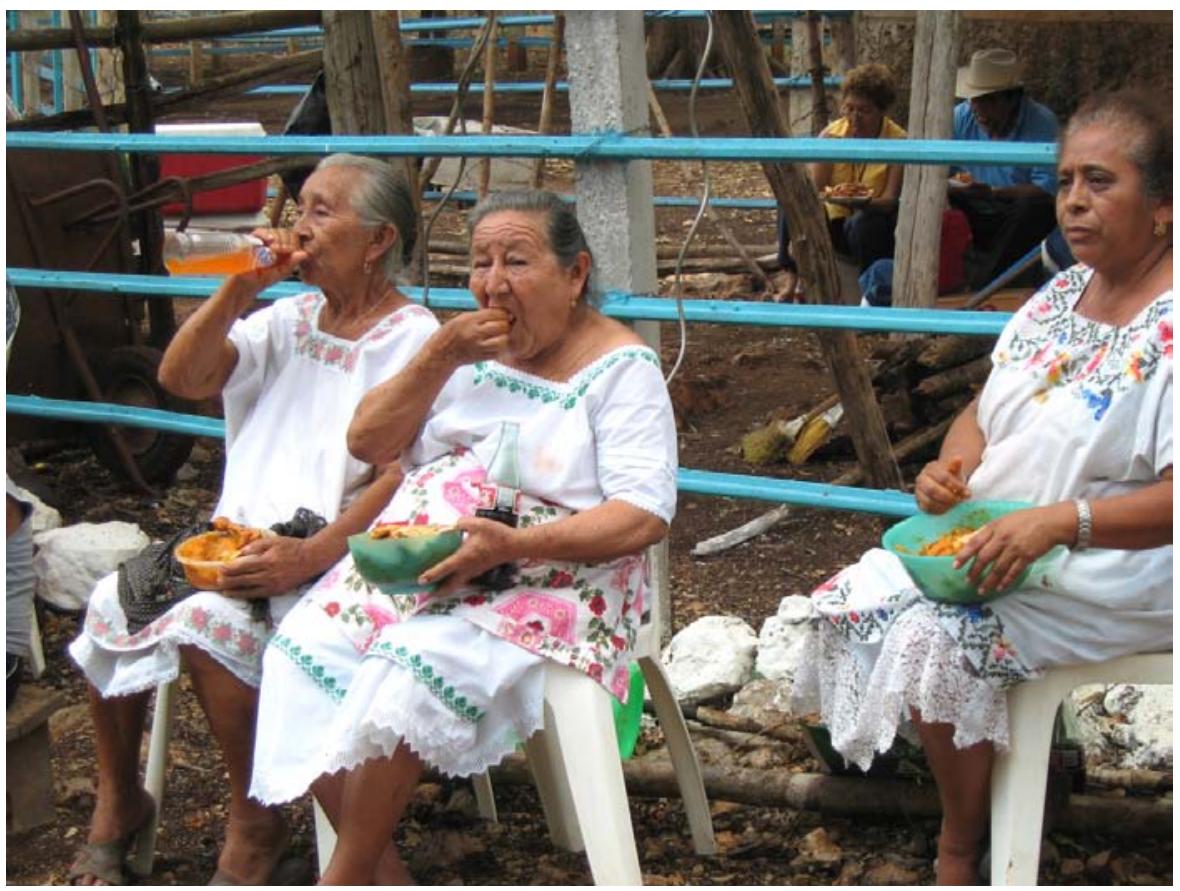

Fotografía 4. El máAtan K’ol (Iván de Jesús Solís Sosa, Muna, Yucatán. 13 de mayo de 2006). 


\section{BIBLIOGRAFÍA}

Barrera Vázquez, Alfredo

1973 “Costumbres y religiosidad del pueblo maya”, Revista de la Universidad autónoma de Yucatán, XVI, (86): 22-40. marzo-abril, Mérida, Yucatán.

, Alfredo Barrera Marín y Rosa María López Franco

1976 Nomenclatura Etnobotánica Maya. Centro Regional del Sureste, Colección Científica Número 36, INAH/SEP, 1976.

, Juan Ramón Bastarrachea Manzano, y William Brito Sansores

1980 Diccionario maya Cordemex. Mérida, Yucatán: Ediciones Cordemex, 1980.

Domínguez Aké, Santiago

1996 La milpa en Muxupip. México: Culturas Populares.

Galinier, Jacques

1995 "El depredador celeste. Notas acerca del sacrificio entre los mazahuas", Anales de antropología 27, pp. 167-251. México: unAm.

Galinier, Jacques

2005 "Campo del ritual, campo del sacrificio". Seminario permanente de Etnografía Mexicana. Proyecto Etnografía de las Regiones Indígenas de México. Coordinación Nacional de Antropología. Del 4 al 30 de octubre InAH, México, D.F.

INEGI

Tabulados Básicos del XII Censo General de Población y Vivienda. 2001.

Lupo, Alessandro

1995 La tierra nos escucha. La cosmología de los nahuas a través de las súplicas rituales. México: Conaculta/INI.

Maás Collí, Hilaria

1991 La importancia de las ceremonias y prácticas religiosas en una comunidad rural, Sotuta, Yucatán. Mérida, Yucatán: Universidad Autónoma de Yucatán. Centro de Investigaciones Regionales “Dr. Hideyo Noguchi” Unidad de Ciencias Sociales.

Turner, Víctor

1999 La selva de los símbolos. Aspectos del ritual ndembu. México: Siglo XXI, 1999.

\section{Fuentes Orales}

Entrevista a Sra. Marcelina Narváez, Muna, Yucatán, 13 de mayo de 2006.

Entrevista a Sra. Marcelina Narváez, Muna, Yucatán, 17 de abril de 2007. 
Entrevista a Sra. Graciela Martín y Gilberto Nah Paredes, Muna, Yucatán, 17 de abril de 2007.

Entrevista al Sr. Fernando Fuentes, Muna, Yucatán 18 de abril de 2007

\section{Fotografías}

Patricia Ma. Balam Gómez

Ileana Ruiz

Iván de Jesús Solís Sosa 
